\title{
Concurrent Sexual Partnerships and Human Immunodeficiency Virus Risk Among South African Youth
}

\author{
Annie E. Steffenson, PhD, MPH${ }^{\star}$, Audrey E. Pettifor, PhD, $\mathrm{MPH}^{\dagger}$, George R. Seage III, ScD, \\ $\mathrm{MPH}^{\ddagger}$, Helen V. Rees, MD, MA ${ }^{\S}$, and Paul D. Cleary, PhD ${ }^{\mathbb{1}}$ \\ "Independent Researcher, San Carlos, CA \\ †Department of Epidemiology, University of North Carolina at Chapel Hill, Chapel Hill, NC \\ ‡Department of Epidemiology, Harvard School of Public Health, Boston, MA \\ §Reproductive Health and HIV Research Unit, University of the Witwatersrand, Johannesburg, \\ South Africa \\ ףYale School of Public Health, Yale School of Medicine, New Haven, CT
}

\begin{abstract}
Background-To estimate the prevalence of concurrency (more than 1 sex partner overlapping in time), the attitudes/behaviors of those engaged in concurrency, length of relationship overlap, and the association between concurrency and human immunodeficiency virus (HIV) among South Africans aged 15 to 24 years.
\end{abstract}

Methods-A cross-sectional, nationally representative, household survey of HIV infection, and sexual attitudes and behaviors was conducted among 11,904 15 to 24 year old South Africans in 2003. Analyses were conducted among sexually experienced youth.

Results-Men were more likely to report having concurrent (24.7\%) than serial partners (5.7\%) in the past 12 months, but concurrency was not associated with HIV. Among women, concurrency and serial monogamy were equally common $(4.7 \%)$, and concurrency, defined by respondent reports of multiple ongoing partners, was associated with HIV in multivariate analysis (odds ratio, $3.4 ; 95 \%$ confidence interval, 1.8-6.5). Median length of relationship overlap was approximately 4 months for women and 3 months for men. Compared to serial monogamists, concurrents reported less consistent condom use, and female concurrents were more likely to report transactional sex and problems negotiating condoms and refusing intercourse.

Conclusions-Concurrency is a common partnership pattern among those youth with multiple partners, especially men. For women, having concurrent relationships may be associated with relationship power imbalances and less ability to protect against HIV. Given the prevalence and likely significance of concurrency in the spread of HIV throughout a sexual network, our findings underscore the need for prevention efforts targeting fidelity.

Researchers have increasingly focused on concurrent sexual partnerships as a critical factor in the spread of human immunodeficiency virus (HIV).${ }^{1-4}$ Few published studies have documented the prevalence of concurrency among general populations in Sub-Saharan Africa, specifically among young adults, the age group at highest risk for HIV. ${ }^{5-7}$

Copyright $@ 2011$ American Sexually Transmitted Diseases Association All rights reserved.

Correspondence: Audrey Pettifor, PhD, MPH, Department of Epidemiology, CB 7435, McGavran-Greenberg Bldg, University of North Carolina at Chapel Hill, Chapel Hill, NC 27599-7435. apettif@email.unc.edu. 
Concurrency has been conceptualized and studied as both an individual and network or population-level risk factor. On a population level, researchers have argued that concurrency may help explain regional variation in HIV epidemics, particularly the enormous HIV burden in east and southern Africa. ${ }^{3,1}$ Modeling studies have shown that with the same number of partners, a higher proportion of concurrency in a network can greatly increase the rate of spread of sexually transmitted infections (STIs). ${ }^{8,9}$ Furthermore, the heightened infectivity associated with primary HIV infection ${ }^{10,11}$ increases the risk associated with concurrency; concurrency creates links that allow the virus to "travel" throughout a network, increasing the probability that an individual will be connected to someone recently infected. ${ }^{12,3}$

Empirical studies suggest that engaging in concurrency increases the chances that an individual will transmit STIs. ${ }^{13,14}$ Researchers using a population-based sample of blacks in the rural southern United States concluded that concurrent partnerships increase HIV risk in that population. ${ }^{15}$ A network level study found that among members of sexual networks in highrisk areas in San Francisco, those whose recent partners reported concurrency were at increased risk for chlamydia and gonorrhea. ${ }^{16}$

Most of the increased individual-level risk of acquiring HIV associated with concurrency results from having a partner who engages in concurrency and thus increases an individual's potential exposure to primary HIV infection by "connecting" that individual to an expanded sexual network. ${ }^{12,17}$ However, researchers have also documented an increased individuallevel risk of acquiring STIs associated with engaging in concurrency oneself. ${ }^{18-21}$ Studies conducted in the United States among STI clinic attendees established that even after controlling for number of partners, both adolescents ${ }^{18}$ and adults ${ }^{19}$ who engaged in concurrency were at increased risk for STIs. In addition, a national survey of adults in the United States indicated that having had concurrent partners was associated with a history of an STI, ${ }^{20}$ and a survey of Seattle residents found that concurrency was associated with STI risk independent of partner number. ${ }^{21}$

Studies conducted outside the United States have yielded similar results. ${ }^{22-24}$ Researchers found an association between having current concurrent partners and Herpes among male bar and hotel workers in Moshi, Tanzania. ${ }^{25}$ In contrast, researchers did not find an association between concurrency and HIV in 5 urban communities in sub-Saharan Africa. ${ }^{5}$ However, there were important limitations to this study, including a failure to account for circumcision. ${ }^{26}$ Studies have generally not assessed why having partners concurrently would increase an individual's risk for acquiring HIV after controlling for number of partners.

In this study, we document the sexual partnership patterns of a general population of youth in South Africa using a nationally representative sample and using multiple measures of concurrency. We test the hypotheses that (1) having concurrent partners or (2) perceiving that partner has concurrent partners are associated with HIV infection, and we describe and compare the behaviors and attitudes of those engaged in different patterns of sexual partnerships. We also measure mean length of sexual relationship overlap of concurrent partnerships.

\section{MATERIALS AND METHODS}

\section{Sample and Study Design}

A household survey of a nationally representative sample of South African youth ages 15 to 24 was conducted from March to August 2003. Subjects were selected using a 3-stage disproportionate, stratified sample. Census enumeration areas were the primary sampling unit. The sample was stratified by province and by area of residence (rural, urban) within 
province. The final sample consisted of 15,414 eligible youth. Of these, 11,904 completed an interview. The response rate was estimated to be $68.2 \%$, based on known eligible and estimated eligible youth. (It was not possible to determine if some of the households had an eligible youth; it was estimated that $40 \%$ of these households had a youth age 15-24.) We restricted the analyses presented herein to respondents who reported having had sexual intercourse or 7692 respondents. Young people were asked to take part in an intervieweradministered, structured, close-ended questionnaire that covered a range of topics related to HIV, including sexual history, HIV knowledge, exposure to HIV programs, condom selfefficacy, and attitudes related to sexual behaviors. All young people were tested for HIV anonymously. The questionnaire was translated from English into Sotho, Zulu, Tswana, Xhosa, Pedi, Venda, Tsonga, and Afrikaans and then back translated. Testing was conducted using Orasure Oral Specimen Collection Device and the Vironostika Uniform II plus O enzyme-linked immunosorbent assay (Biomerieux). Informed consent was obtained from all respondents and parents of 15 to 17 year olds. This study was approved by the ethics committee at the University of the Witwatersrand in South Africa.

\section{Measures}

Individual's Concurrency-One challenge in examining the prevalence of concurrency in a given country is the variation in definition and measures of concurrency. In 2009, the UNAIDS Reference Group on Estimates, Modelling, and Projections published a working definition of concurrency as: "overlapping sexual partnerships in which sexual intercourse with 1 partner occurs between 2 acts of intercourse with another partner." 27 In addition, they recommend that the time frame for measuring concurrency be the 6 months before the interview.

Respondents who reported more than 1 sexual partner in the past 12 months were administered a detailed partner grid that captured partner specific information on the 3 most recent sex partners in the past 12 months. We measured concurrency ("concurrents") using following 2 methods.

1. Respondents were asked the date in month and year of the first and last time they had sex with each of their last 3 partners in the past 12 months. Those who reported overlapping dates for more than 1 partner were categorized as having concurrent relationships. This measure is considered the gold standard for assessing concurrency. ${ }^{27}$ For respondents who first had sex with a partner more than 12 months before the interview, there may be issues with recall accuracy. Therefore, analyses were also conducted among individuals who reported having 2 or more concurrent sex partners using only relationships for which concurrency occurred in the 6 months (180 days) preceding the interview—as recommended by UNAIDS. ${ }^{27}$

2. The second measure of concurrency was assessed based on a question that was asked of respondents for each partner in the past 12 months. For each partner, respondents were asked "Is this sexual relationship ongoing or has it ended?" If a respondent reported having more than 1 relationship that was ongoing we defined them as engaging in concurrency. We used this question as a second measure because there may be recall error with regard to accuracy of dates of first and last sex in partnerships which could result in either over or under reporting of concurrency. This second measure may be less prone to recall error but more prone to social desirability bias.

Respondents whose partnership patterns we could not accurately categorized were excluded from analyses. Therefore, we excluded (1) respondents who had the same month of first sex with a more recent partner and last sex with a previous partner because it could not be determined if the relationships overlapped in time (and thus were concurrent) or if there was 
a gap between partnerships; (2) respondents with more than 3 relationships in the past year if the most recent 3 were serial. These respondents are excluded because information is only available on up to 3 most recent partners. Those with more than 3 partners may have overlapping dates with partners for whom information is not available; (3) respondents who only had dates for relationships that ended more than 12 months ago because all relationships were meant to be in the last 12 months. In total, 122 men and 30 women were excluded.

Respondents who reported more than 1 partner in the past 12 months and were not defined as having a concurrent relationship using the above methods are referred to as serial monogamists.

Perceptions of Partner's Concurrency-Respondents who reported having a main partner at the time of the survey were asked if they agree/disagree with the statement "My partner is faithful that is they have no other partners." Those who disagreed with this statement were categorized as having a partner who engaged in concurrency.

\section{Length of Sexual Relationship and Length of Sexual Relationship Overlap-}

We estimated the median length of each sexual relationship in days among respondent who reported having concurrent partners and among respondents who reported having multiple partners that were separated by gaps (serial monogamists). We estimated the median length of relationship overlap in days for respondents who reported having concurrent relationships. The lengths of sexual relationships are measured as the time between the first and last sexual intercourse with a given partner. The lengths are estimates because dates for first and last sexual intercourse were recorded as month and year. It is therefore impossible to determine exact length of relationship or overlap. Relationships that have first and last sex in the same month are estimated to last 15 days, and the length of relationships from 1 month to the next (e.g., July 03-August 03) are estimated to last 30 days.

\section{Statistical Methods}

Data were weighted to be representative of South African youth ages 15 to 24 years. All tests of statistical significance were adjusted to account for the survey design and weights. Chi-squared tests were used to test differences between respondents who reported having concurrent partnerships compared to those who reported only having serially monogamous relationships.

Bivariate analyses were conducted to identify candidate variables for the multivariate regression analysis (results not shown) ${ }^{28}$ Confidence intervals (CIs) were calculated for the estimated associations between HIV infection and correlates of infection.

Multivariate logistic regression was used to determine the relationship between having engaged in concurrency or having a partner who engaged in concurrency and HIV status while controlling for influential demographic characteristics, HIV risk behaviors, and sexual health characteristics. Models were stratified by gender. Multiple models were used to explore different measures of concurrency. The models included factors found to be significant in bivariate analyses $(P \leq 0.05)$ estimating the association between HIV and demographic, behavioral, and attitudinal correlates of infection (results not shown), and those theorized, a priori, to be important HIV risk factors. While attitudinal variables, transactional sex, and perceptions of partner's fidelity were not found to be significant correlates of HIV infection in bivariate analysis, we explored them as potential mediators of the association between HIV and concurrency. Their inclusion in the multivariate model did not alter the substantive findings on the relationship between concurrency and HIV and they 
were excluded from the final model. All analyses were conducted using STATA 8.0 (College Station, TX).

\section{RESULTS}

\section{Sample Characteristics}

Almost 1 in $5(21.6 \%)$ sexually experienced women and $5.9 \%$ of sexually experienced men were HIV-positive (Table 1). About 4 in $10(40.6 \%)$ men and almost half $(47.2 \%)$ of women had no education or less than a high school education. A majority $(75.2 \%)$ of men reported more than 1 lifetime sexual partner and inconsistent condom use with most recent partner $(60.8 \%)$ as did a majority of women $(54.6 \%, 71.4 \%$, respectively). When asked to categorize their most recent partner, the majority $(82.3 \%)$ of men and women $(98.5 \%)$ said a "main" partner. Additional details of the sample are presented in Pettifor et al., 2005. ${ }^{28}$

\section{Partnership Patterns and Partner Fidelity}

Among male participants close to $25 \%$ reported having concurrent partnerships in the past 12 months while $5.7 \%$ reported serial monogamy (Table 2). Among young women, the majority (76.3\%) of participants reported having had only 1 partner in the past 12 months. Only $4.7 \%$ of young women reported having had concurrent relationships in the past 12 months and $4.7 \%$ reported having had serially monogamous relationships.

Among women, about a third (33.8\%) disagreed with the statement, "My partner is faithful, that is they have no other partners," indicating that their partner was engaged in concurrency. Fewer men (18.2\%) believed their partner was engaging in concurrency.

\section{Length of Relationship Overlap}

For participants who reported concurrent partnerships, the approximate median length of relationship overlap was 3 months for men and 4 months for women.

\section{Concurrents Compared to Serial Monogamists}

Men who reported having concurrent partnerships were more likely than those reporting serially monogamous relationships to be black/African (94.6\% vs. $81.1 \%$ ) and older (Table 3 ). They also reported a higher mean number of lifetime sex partners (7.7 vs. 5.1) and in the past 12 months ( 2.9 vs. 2.2). They were less likely to report consistent condom use and reported more regular casual partners but fewer nonregular casual partners.

Among women, partnership patterns did not vary by race. Like men, concurrent women were older than serial monogamists. While the mean lifetime number of sexual partners was similar, concurrents reported more partners in the past year ( $2.2 \mathrm{vs.} 2.0)$. They were also about half as likely to report consistent condom use ( $21 \%$ vs. $41.4 \%)$ or condom use during last intercourse. Concurrents were more likely to report engaging in transactional sex (5.3\% vs. $1.4 \%)$, a genital sore in the past 12 months ( $15.4 \%$ vs. $5.2 \%)$, and having ever been pregnant $(41.4 \%$ vs. $24.8 \%)$.

Male serial monogamists and concurrents differed significantly on only 2 attitudes (Table 3). Concurrent men were more likely to agree that "it is okay to have many sexual partners" (14.1\% vs. 5.6\%), but less likely to agree that "it is cool to have a partner who is older than you" (15.6\% vs. $23.6 \%)$. Concurrents and serial monogamist men were about equally likely to report that their partner is faithful.

Among women, concurrents were more likely to agree that "using a condom is a sign of not trusting your partner" (33.2\% vs. $20.6 \%$ ) and almost 1 in 10 responded no or probably no 
when asked if they would be able to talk about using condoms with their partner. Concurrent women were also more likely to agree that "there are times when I do not want to have sex, but I do because my partner insists on having sex" (39.6\% vs. 22.9\%). Concurrent and serial monogamist women did not differ on the relationship control index and reported partner fidelity.

\section{Concurrency and HIV}

The unadjusted relationship between HIV and concurrency varied by gender and by the measure of concurrency (Table 4). Having a partner who engaged in concurrency was not associated with HIV infection for men or women. The association between engaging in concurrency oneself and HIV was also nonsignificant when concurrency was defined as those who reported either ongoing partnerships and/or overlapping sexual relationship dates, and was not significant when we looked at those who reported overlapping dates in the past 12 months. However, when we looked at each measure of concurrency separately and limited those who reported overlapping dates to the past 6 months, we found significant associations with HIV among men and women. Among women, those who reported more than 1 current ongoing relationship $(n=95)$ were over 3 times more likely than those who did not to be HIV-positive (odds ratio, 3.4; 95\% CI, 1.8-6.5). Among men, those who reported relationship dates that overlapped in the past 6 months $(n=603)$ were more likely than those who did not to be HIV-positive (odds ratio, 1.6; 95\% CI, 1.1-2.3) (Table 4).

After controlling for key demographic characteristics and risk factors, the relationship between concurrency, defined as overlapping relationship dates in the past 6 months, and HIV among young men was no longer significant (Table 5). Among women, concurrency defined as more than 1 ongoing sexual relationship was significantly associated with HIV infection even after controlling for demographic and high risk variables $(2.5$; 95\% CI, $1.3-$ 4.3).

\section{DISCUSSION}

We found that around $25 \%$ of young men and just under $5 \%$ of young women reported engaging in concurrent relationships in the last 12 months. Concurrency was more common than serial monogamy among young men in South Africa. While young women were less likely to engage in concurrency than young men, those with multiple partners in the past 12 months were just as likely to report that their relationships occurred concurrently as sequentially. The prevalence of concurrency reported in this nationally representative survey is similar to that reported in a 2005 household based survey of young people ages 16 to 26 in Cape Town, South Africa where $20.2 \%$ of young men and $6.2 \%$ of young women reported engaging in concurrent relationships. ${ }^{6}$

Almost a third of young women (33.8\%) and about 1 in 5 young men (18.2\%) believed their partner was not faithful. It is unclear whether respondents are overestimating their partners' infidelity or inaccurately reporting their own or both. The discordance between the proportions of women who reported engaging in concurrency compared to the proportion of men who indicated that their partner was unfaithful suggests that young women may be underreporting the number of sex partners they have, including concurrent partnerships. Other studies have found that among couples, agreement between perceptions of sex-partner concurrency and partner-reported behavior was low, with women underreporting their number of sex partners and men over reporting, and that misperceptions about partner fidelity increases the risk for STI infection. ${ }^{17,32-34}$

On an individual-level, 1 measure of concurrency, having multiple ongoing partners, was associated with HIV among young women even after controlling for key demographic and 
risk variables. This suggests that understanding the dynamics of this partnership pattern is relevant to understanding young women's risk, and the risk associated with multiple sexual partners. Among men, engaging in concurrency was not associated with HIV infection in the final multivariable model. Perceptions of having a partner who engaged in concurrency was not associated with HIV for men or women in this population.

We do not know why engaging in concurrency increased a woman's risk for HIV after controlling for number of partners. Having multiple concurrent partners may place the index case at increased risk of being exposed to an STI which would increase the risk of HIV acquisition. It also may be a marker for engaging in other risky behaviors or being part of a sexual network that is higher risk and that may have a higher prevalence of HIV infection. ${ }^{26}$ We found that young women who reported having concurrent sex partners also reported riskier sexual behaviors and attitudes compared to young women who were serially monogamous that may place them at increased risk of infection. A comparison of attitudes between concurrents and serial monogamists suggests that concurrents may be in relationships with more severe male-female power imbalances. Some of their attitudes suggest problems negotiating condom use and difficulty refusing unwanted sexual intercourse. Studies have found an association between a lack of control in a relationship and HIV risk. ${ }^{35,36}$

Women in concurrent relationships were more likely to report engaging in transactional sex. The reported rates of transactional sex among concurrents are still low, though the question measuring transactional sex may not be nuanced enough to capture the true prevalence. This transactional exchange may further exacerbate gender imbalances around intercourse.

Further studies are needed to determine the extent to which exchange or material support is present in concurrent relationships.

Our data do not allow us to measure network-level risk associated with concurrency. However, the prevalence of reported concurrency among men underscores the potential for this behavioral pattern to be a factor in the HIV epidemic. Our findings also suggest that those who have concurrent relationships generally have a second ongoing partnership rather than an occasional one-night relationship which also has implications for the role of concurrency in the spread of HIV. Studies indicate that condoms are generally used inconsistently in longer-term relationships compared to one-night stands. ${ }^{37}$ Indeed, we found that male concurrents were more likely to report inconsistent condom use than were serial monogamists.

We measured concurrency using 2 measures, allowing us to potentially capture more individuals who engage in concurrency. Each measure, however, has potential biases. Because of the social pressure on young South African men to have multiple sexual partners, men may be more likely to overreport the number of "ongoing" partnerships they have, while all respondents may have difficulty accurately recalling dates of intercourse. The fact that concurrency defined as multiple ongoing partners was a significant risk factor for HIV among women, while concurrency defined as overlapping dates was not, suggests potential problems with 1 or both measures. Another limitation of our study is that given the crosssectional nature of the study, we cannot determine when the young people were infected with HIV so it is unclear if concurrent behaviors reported in the past 6 to 12 months resulted in infection with HIV. Another potential source of bias is the fact that we could not accurately categorize, and were thus forced to exclude from analysis, those serial monogamists who had more than 3 partners in the past 12 months ( 23 men and 1 woman). 


\section{Policy Implications}

"A, B, C" prevention programs have been underway in sub-Saharan Africa for years with limited success. Prevention efforts have been more successful in Uganda where campaigns focused heavily on partner reduction and faithfulness. Researchers have argued that the emphasis on fidelity, especially early in the epidemic, may explain why Uganda succeeded where others have failed. ${ }^{38}$

Other campaigns in Africa have not emphasized faithfulness as heavily as abstinence and condom use. ${ }^{1,4} \mathrm{We}$ found that close to one-quarter of young men in this population reported having concurrent relationships in the past year suggesting the potential importance of prevention messages more explicitly emphasizing fidelity. When asked to describe in their own words how to prevent HIV/AIDS, only $10 \%$ of respondents mentioned having 1 faithful partner compared to $77 \%$ who mentioned condom use and $41 \%$ who mentioned abstinence. ${ }^{39}$ Recently, a decline in estimated incidence in South Africa among young people has been reported. One explanation is a significant increase in condom use among the population. Changes in partner numbers have not been observed. It may be that to achieve greater declines in incidence in South Africa, partner number and/or concurrency must also decrease. ${ }^{40}$ Future research, policy, and program initiatives also need to address social norms that support concurrency, as well as the contextual and structural barriers to fidelity.

Our estimate of the prevalence of concurrency in a nationally representative sample of young adults in sub-Saharan Africa addresses a critical gap in the literature. The debate about the role of concurrency in the size or spread of the epidemic in sub-Saharan Africa stems in part from the lack of empirical data on the prevalence of concurrency in the population and the association with incident infection. ${ }^{41,42}$ This study is an important first step and suggests that further studies on concurrency are needed.

\section{Acknowledgments}

Supported by an NIH/NIAID T32 Program for AIDS Clinical Research Training Grant (NIAID AI 007433) (to A.E.S.), and by the Henry J. Kaiser Family Foundation.

\section{REFERENCES}

1. Potts M, Halperin DT, Kirby D, et al. Reassessing HIV prevention. Science. 2008; 320:749-750. [PubMed: 18467575]

2. Hudson CP. AIDS in rural Africa: A paradigm for HIV-1 prevention. Int J STD AIDS. 1996; 7:236243. [PubMed: 8876353]

3. Halperin DT, Epstein H. Concurrent sexual partnerships help to explain Africa's high HIV prevalence: Implications for prevention. Lancet. 2004; 364:4-6. [PubMed: 15234834]

4. Epstein, H. The fidelity fix. New York Times: Jun 13. 2004

5. Lagarde E, Auvert B, Carael, et al. Concurrent sexual partnerships and HIV prevalence in five urban communities of sub-Saharan Africa. AIDS. 2001; 15:877-884. [PubMed: 11399960]

6. Mah TL. Prevalence and correlates of concurrent sexual partnerships among young people in South Africa. Sex Transm Dis. 2010; 37:105-108. [PubMed: 19823109]

7. Carter MW, Craft JM, Koppenhaver J, et al. "A bull cannot be contained in a single kraal": Concurrent sexual partnerships in Botswana. AIDS Behav. 2007; 11:822-830. [PubMed: 17295072]

8. Morris M, Kretzschmar M. Concurrent partnerships and the spread of HIV/AIDS. AIDS. 1997; 11:681-683. [PubMed: 9108951]

9. Watts CH, May RM. The influence of concurrent partnerships on the dynamics of HIV/AIDS. Math Biosci. 1992; 108:89-104. [PubMed: 1551000] 
10. Quinn TC, Wawer MJ, Sewankambo N, et al. Viral load heterosexual transmission of human immunodeficiency virus type 1 Rakai Project Study Group. N Engl J Med. 2000; 342:921-929. [PubMed: 10738050]

11. Gray RH, Wawer MJ, Brookmeyer R, et al. Probability of HIV-1 transmission per coital act in monogamous, heterosexual, HIV-1-discordant couples in Rakai, Uganda. Lancet. 2001; 357:1149_ 1153. [PubMed: 11323041]

12. Morris M. Concurrent partnerships and syphilis persistence: New thoughts on an old puzzle. Sex Transm Dis. 2001; 28:504-507. [PubMed: 11518866]

13. Koumans EH, Farley TA, Gibson JJ, et al. Characteristics of persons with Syphilis in areas of persisting syphilis in the United States. Sex Transm Dis. 2001; 28:497-503. [PubMed: 11518865]

14. Potteratt JJ, Zimmerman-Rogers H, Muth SQ, et al. Chlamydia transmission concurrency, reproduction number, and the Epidemic trajectory. Am J Epidemiol. 1999; 150:1331-1339. [PubMed: 10604776]

15. Adimora AA, Schoenbach VJ, Martinson F, et al. Concurrent sexual partnerships among African Americans in the rural south. Ann Epidemiol. 2004; 14:155-160. [PubMed: 15036217]

16. Ellen JM, Brown BA, Chung S, et al. Impact of sexual networks on risk for gonorrhea and Chlamydia among low-income urban African American adolescents. J Pediatr. 2005; 146:518 522. [PubMed: 15812456]

17. Drumright LN, Gorbach PM, Holmes KK. Do people really know their sex partners? Concurrency, knowledge of partner behavior, and sexually transmitted infections within partnerships. Sex Trans Dis. 2004; 31:437-442.

18. Rosenberg MD, Gurvey JE, Adler N, et al. Concurrent sex partners and risk for sexually transmitted diseases among adolescents. Sex Transm Dis. 1999; 26:208-212. [PubMed: 10225587]

19. Gorbach PM, Drumright LN, Holmes KK. Discord, discordance, and concurrency: Comparing individual and partnership-level analyses of new partnerships of young adults at risk of sexually transmitted infections. Sex Transm Dis. 2005; 32:7-12. [PubMed: 15614115]

20. Laumann, EO.; Gagnon, JH.; Michael, RT., et al. The Social Organization of Sexuality: Sexual Practices in the United States. Chicago, IL: University of Chicago Press; 1994.

21. Manhart LE, Aral SO, Holmes KK, et al. Sex partner concurrency: measurement, prevalence, and correlates among urban 18-39-year-olds. Sex Transm Dis. 2002; 29:133-143. [PubMed: 11875374]

22. Castor D, Jolly PE, Furlonge C, et al. Determinants of gonorrhoea infection among STD clinic attenders in Trinidad-II: Sexual behavioural factors. Int J STD AIDS. 2002; 13:46-51. [PubMed: 11802930]

23. Gregson S, Nyamukapa CA, Garnett GP, et al. Sexual mixing patterns and sex-differentials in teenage exposure to HIV infection in rural Zimbabwe. Lancet. 2002; 359:1896-1903. [PubMed: 12057552]

24. Dunkle KL, Jewkes RK, Brown HC, et al. Gender-based violence, relationship power, and risk of HIV infection in women attending antenatal clinics in South Africa. Lancet. 2004; 363:14151421. [PubMed: 15121402]

25. Kapiga SH, Sam NE, Shao JF, et al. Herpes simplex virus type 2 infection among bar and hotel workers in northern Tanzania: Prevalence and risk factors. Sex Transm Dis. 2003; 30:187-192. [PubMed: 12616132]

26. Mah TL, Halperin DT. Concurrent sexual partnerships and the HIV epidemics in Africa: Evidence to move forward. AIDS Behav. 2010; 14:11-16. discussion 34-37. [PubMed: 18648926]

27. UNAIDS Reference Group on Estimates, and Modelling, Projections: Working Group on Measuring Concurrent Sexual Partnerships. HIV: Consensus indicators are needed for concurrency. Lancet. 2010; 375:621-622. [PubMed: 19954832]

28. Pettifor AE, Rees HV, Kleinschmidt I, et al. Young people's sexual health in South Africa: HIV prevalence and sexual behaviors from a nationally representative household survey. AIDS. 2005; 19:1525-1534. [PubMed: 16135907]

29. Pettifor AE, Measham DM, Rees HV, et al. Sexual power and HIV risk, South Africa. Emerg Infect Dis. 2004; 10:1996-2004. [PubMed: 15550214] 
30. Pulerwitz J, Gortmaker SL, De Jong W. Measuring sexual relationship power in HIV/STD research. Sex Roles. 2000; 42:637-650.

31. Pulerwitz J, Amaro H, De Jong W, et al. Relationship power, condom use and HIV risk among women in the USA. AIDS Care. 2002; 14:789-800. [PubMed: 12511212]

32. Nnko S, Boerma JT, Urassa M, et al. Secretive females or swaggering males? An assessment of the quality of sexual partnership reporting in rural Tanzania. Social Sci Med. 2004; 59:299-310.

33. Helleringer, S.; Kohler, HP.; Chimbiri, A., et al. The Likoma Network Study: Context, data collection and initial results University of Pennsylvania, Population Studies Center, PSC Working Paper Series PSC 07-05. 2007. Available at: http://repository.upenn.edu/pscworkingpapers/9.

34. Lenoir CD, Adler NE, Borzekowski DL, et al. What you don't know can hurt you: Perceptions of sex-partner concurrency and partner-reported behavior. J Adolesc Health. 2006; 38:179-185. [PubMed: 16488813]

35. Dunkle KL, Jewkes R, Nduna M, et al. Transactional sex with casual and main partners among young South African men in the rural Eastern Cape: Prevalence, predictors, and associations with gender-based violence. Soc Sci Med. 2007; 65:1235-1248. [PubMed: 17560702]

36. Jewkes RK, Dunkle K, Nduna M, et al. Intimate partner violence, relationship power inequity, and incidence of HIV infection in young women in South Africa: A cohort study. Lancet. 2010; 376:41-48. [PubMed: 20557928]

37. Lagarde E, Auvert B, Chege J, et al. Condom use and its association with HIV/sexually transmitted diseases in four urban communities of sub-Saharan Africa. AIDS. 2001; 15:S71-S78. [PubMed: $11686468]$

38. Halperin DT, Epstein H. Why is HIV prevalence so severe in Southern Africa? S Afr J HIV Med. 2007; 26:19. Available at: www.harvardaidsprp.org/research/halperin\&epstein-why-is-hivprevalence-so-severe.pdf.

39. Pettifor, A.; Rees, H.; Steffenson, A., et al. HIV and sexual behaviour among young South Africans: A national survey of 15-24 year olds. Johannesburg, South Africa: Reproductive Health Research Unit, University of the Witwatersrand; 2004.

40. Rehle TM, Hallett TB, Shisana O, et al. A decline in new HIV infections in south africa: Estimating HIV incidence from three national HIV surveys in 2002, 2005 and 2008. PLoS One. 2010; 5:e11094. [PubMed: 20559425]

41. Lurie M, Rosenthal S. Concurrent partnerships as a driver of the HIV epidemic in Sub-Saharan Africa? The evidence is limited. AIDS Behav. 2010; 14:17-24. discussion 25-28. [PubMed: 19488848]

42. Shelton JD. Why multiple sexual partnerships? Lancet. 2009; 374:367-368. [PubMed: 19647597] 
TABLE 1

Weighted Proportions HIV, Demographic Characteristics, Sexual Behaviors, and Sexual Health Characteristics Among Sexually Experienced Men and Women, Age 18-24, South Africa, 2003*

\begin{tabular}{|c|c|c|}
\hline & $\begin{array}{c}\text { Men } \\
\mathrm{n}=\mathbf{3 6 2 6}\end{array}$ & $\begin{array}{c}\text { Women } \\
\mathrm{n}=\mathbf{4 0 6 6}\end{array}$ \\
\hline \multicolumn{3}{|l|}{ HIV serostatus } \\
\hline HIV positive & 5.9 & 21.6 \\
\hline \multicolumn{3}{|l|}{ Demographics } \\
\hline Black/African & 85.5 & 88.4 \\
\hline Urban residence (vs. rural) & 55.1 & 52.7 \\
\hline Age $15-19$ (vs. 20-24) & 58.9 & 64.1 \\
\hline No education or less than high school education completed (vs. in school, completed high school or higher) & 40.6 & 47.2 \\
\hline \multicolumn{3}{|l|}{ Sexual behaviors/experiences } \\
\hline$>1$ lifetime sexual partners & 75.2 & 54.6 \\
\hline$>1$ sexual partners in past $12 \mathrm{mo}$ & 44.2 & 12.1 \\
\hline Did not always use condom with most recent partner (vs. always) & 60.8 & 71.4 \\
\hline Did not use condom during last sexual intercourse & 43.2 & 52.0 \\
\hline \multicolumn{3}{|l|}{ Partner type at last sex ${ }^{\dagger}$} \\
\hline Main partner & 82.3 & 98.5 \\
\hline Regular casual & 12.4 & 1.1 \\
\hline Nonregular casual & 5.2 & 0.0 \\
\hline \multicolumn{3}{|l|}{ Age difference with most recent partner } \\
\hline Same age or younger & 88.4 & 9.5 \\
\hline $1-4$ yr older & 10.4 & 59.5 \\
\hline 5 or more yr older & 1.2 & 31.0 \\
\hline Time since coital debut >12 mo (vs. $₫ 2$ mo) & 89.5 & 84.3 \\
\hline Age of coital debut $\unlhd 4 \mathrm{yr}$ old & 17.6 & 7.8 \\
\hline Ever engaged in transactional sex & 3.5 & 2.1 \\
\hline Ever been physically forced to have sex & 2.0 & 9.6 \\
\hline \multicolumn{3}{|l|}{ Sexual health characteristics } \\
\hline Reports unusual genital discharge in past $12 \mathrm{mo}$ & 9.2 & 19.2 \\
\hline Reports genital ulcers/sores in past $12 \mathrm{mo}$ & 5.9 & 6.9 \\
\hline Not circumcised & 65.5 & - \\
\hline Ever pregnant & - & 49.5 \\
\hline
\end{tabular}

* Slight differences in findings between this and a previously published article (Pettifor et al., 2004) are due to slight differences in how the variables were coded. The only exception to this is the "length of time since coital debut" variable, which was calculated differently. For this article, this variable measures the length of time between the interview date and the reported date of first intercourse. For Pettifor et al., 2005, this variable measures the length of time between the age of first sex and the age at time of interview.

${ }^{\dagger}$ Main partner was defined as husband/wife or main girlfriend/ boyfriend. "Regular casual" partner was defined as someone other than the main partner that the respondent had sex with on an ongoing basis. "Nonregular casual" partner was defined as someone other than the main partner that the respondent did not have sex with on an ongoing basis. 
TABLE 2

Reported Partnership Patterns Among Sexually Experienced Men and Women for the Past 12 Months, Age 18-24, South Africa, 2003 (Weighted Proportions)*

\begin{tabular}{|c|c|c|c|c|}
\hline & \multicolumn{2}{|c|}{ Men } & \multicolumn{2}{|c|}{ Women } \\
\hline & $\mathbf{n}$ & $\%$ & $\mathbf{n}$ & $\%$ \\
\hline \multicolumn{5}{|l|}{ Partnership patterns } \\
\hline Concurrent partners ${ }^{\dagger}$ & 915 & 24.7 & 229 & 4.7 \\
\hline Definition 1: ongoing partnerships & 580 & 16.4 & 95 & 1.9 \\
\hline Definition 2: overlapping dates & 775 & 21.6 & 207 & 3.8 \\
\hline Serial partners $\%$ & 234 & 5.7 & 191 & 4.7 \\
\hline No sex past 12 mo & 601 & 21.2 & 442 & 13.3 \\
\hline One partner in past $12 \mathrm{mo}$ & 1720 & 43.9 & 3160 & 76.3 \\
\hline Cannot categorize & 122 & 3.2 & 30 & 0.6 \\
\hline Missing, refused & 34 & 1.3 & 14 & 0.5 \\
\hline Total & 3626 & 100 & 4066 & 100.1 \\
\hline \multicolumn{5}{|l|}{ Partner fidelity $\mathcal{S}$} \\
\hline Partner engaged in concurrency & 744 & 18.2 & 1244 & 33.8 \\
\hline Partner not engaged in concurrency & 2005 & 56.3 & 2284 & 54.2 \\
\hline Youth does not currently have main partner/refused & 877 & 25.5 & 538 & 12.0 \\
\hline Total & 3626 & 100 & 4066 & 100 \\
\hline
\end{tabular}

* Respondents categorized based on a series of questions that ask about sexual experience in the past 12 months, and detailed questions about the 3 most recent sexual partners including dates of first and last intercourses.

${ }^{\dagger}$ Concurrent by definition 1 and/or 2 .

${ }^{t}$ Respondents who report more than 1 serial partner in the past 12 months.

$\xi$ Asked of those youth who currently had a main partner at time of survey. Respondent's partner's fidelity based on question that asks respondents to agree/disagree with statement: "My partner is faithful, that is they have no other partners." 


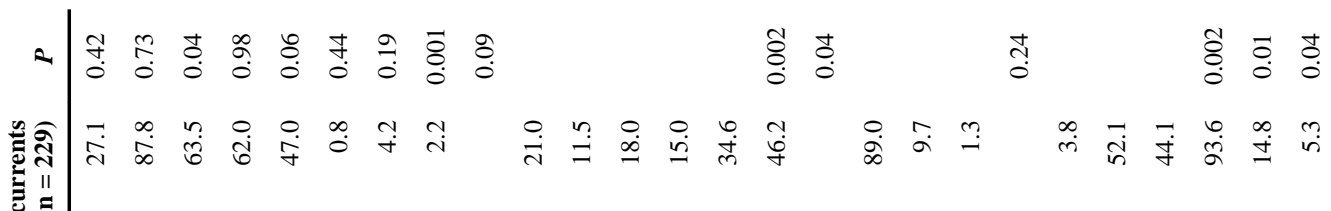

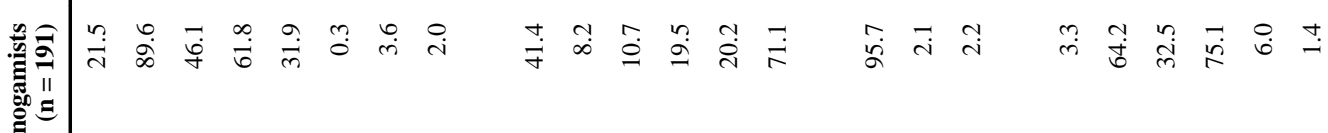

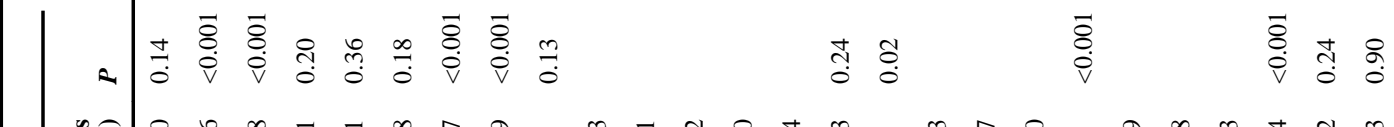

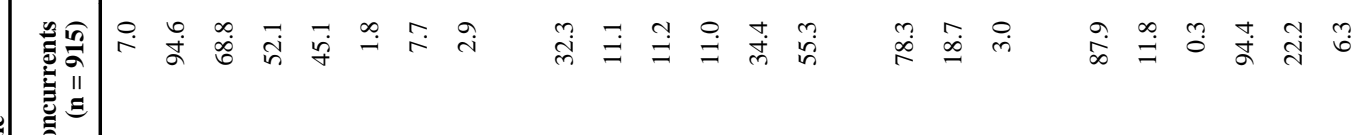

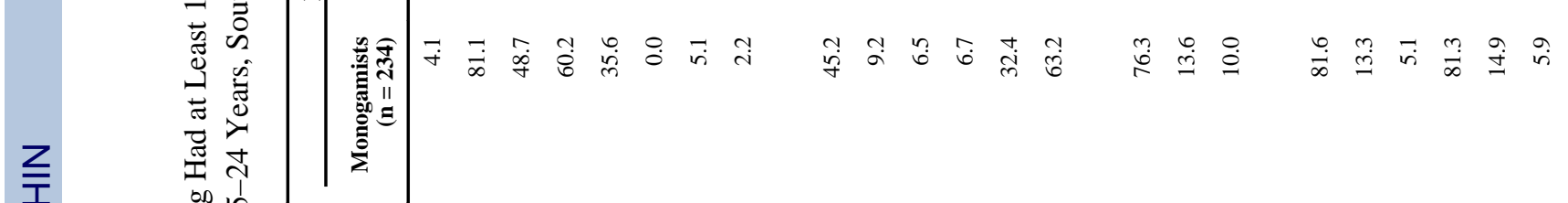




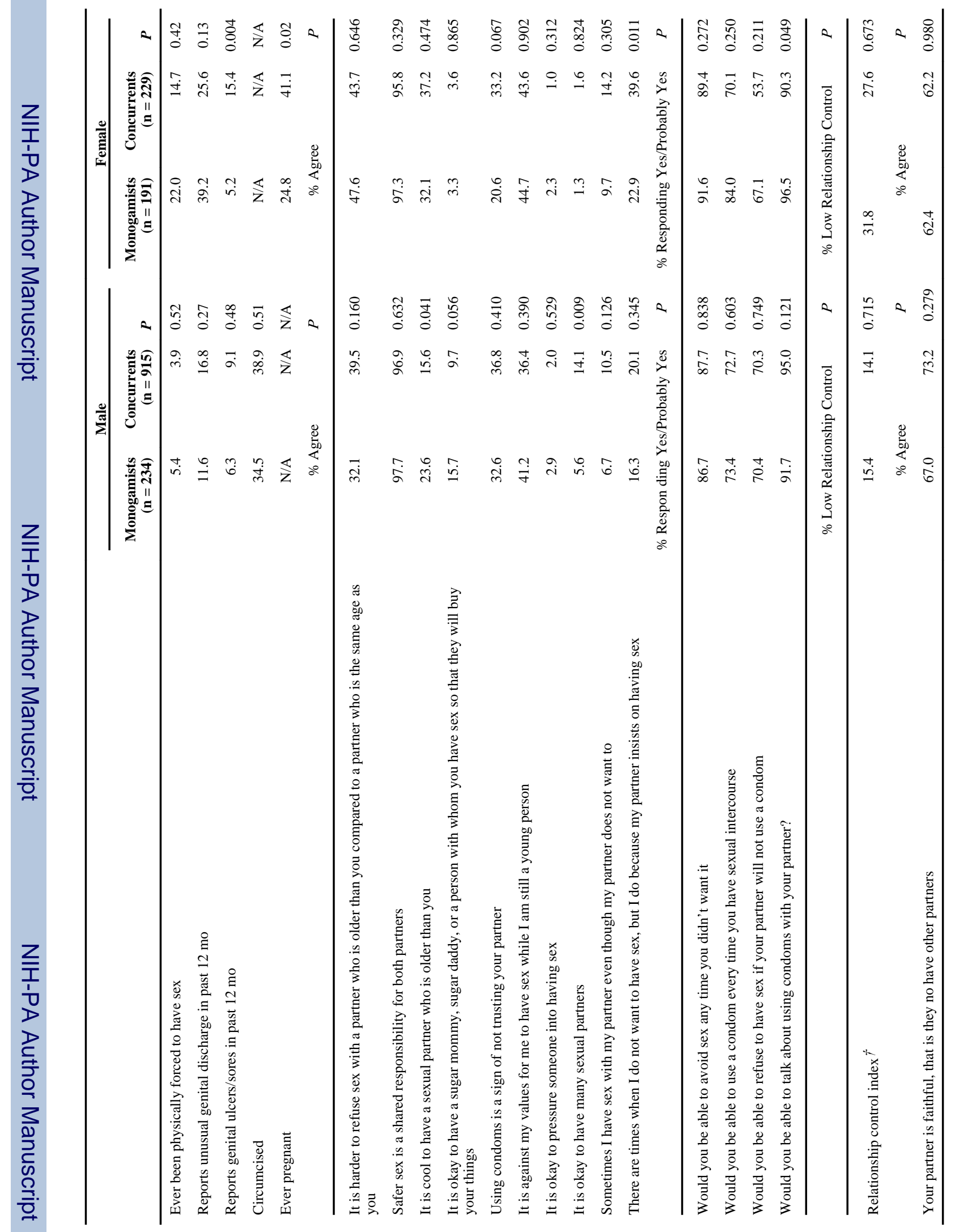




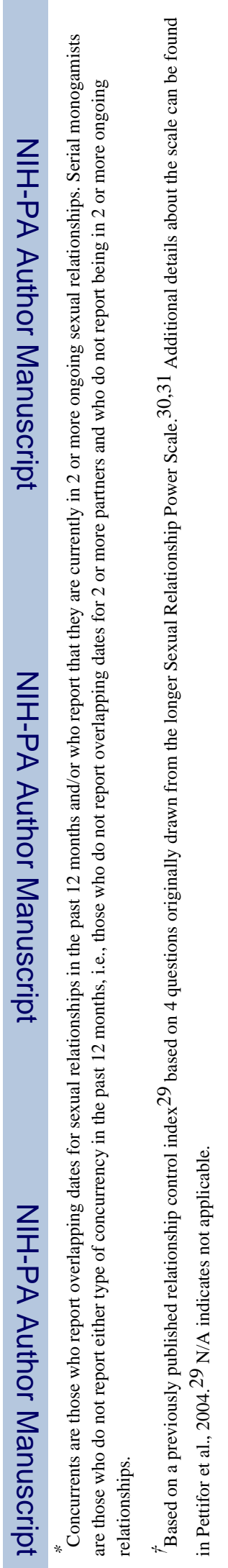


$\pi_{0 \infty}^{\infty} \sum^{\infty}$

$\stackrel{\infty}{\equiv} \stackrel{0}{0}$

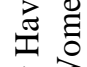

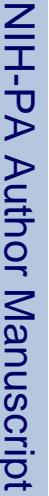

$\stackrel{0}{=}$

远

它

氙

प्ष

.

定交

.0ิ

岂

寻藏

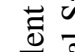

可

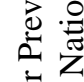

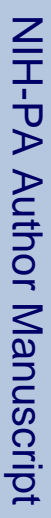

产 究

山 $\sum^{\pi}$

2

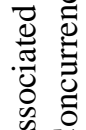

文

를.

จ 


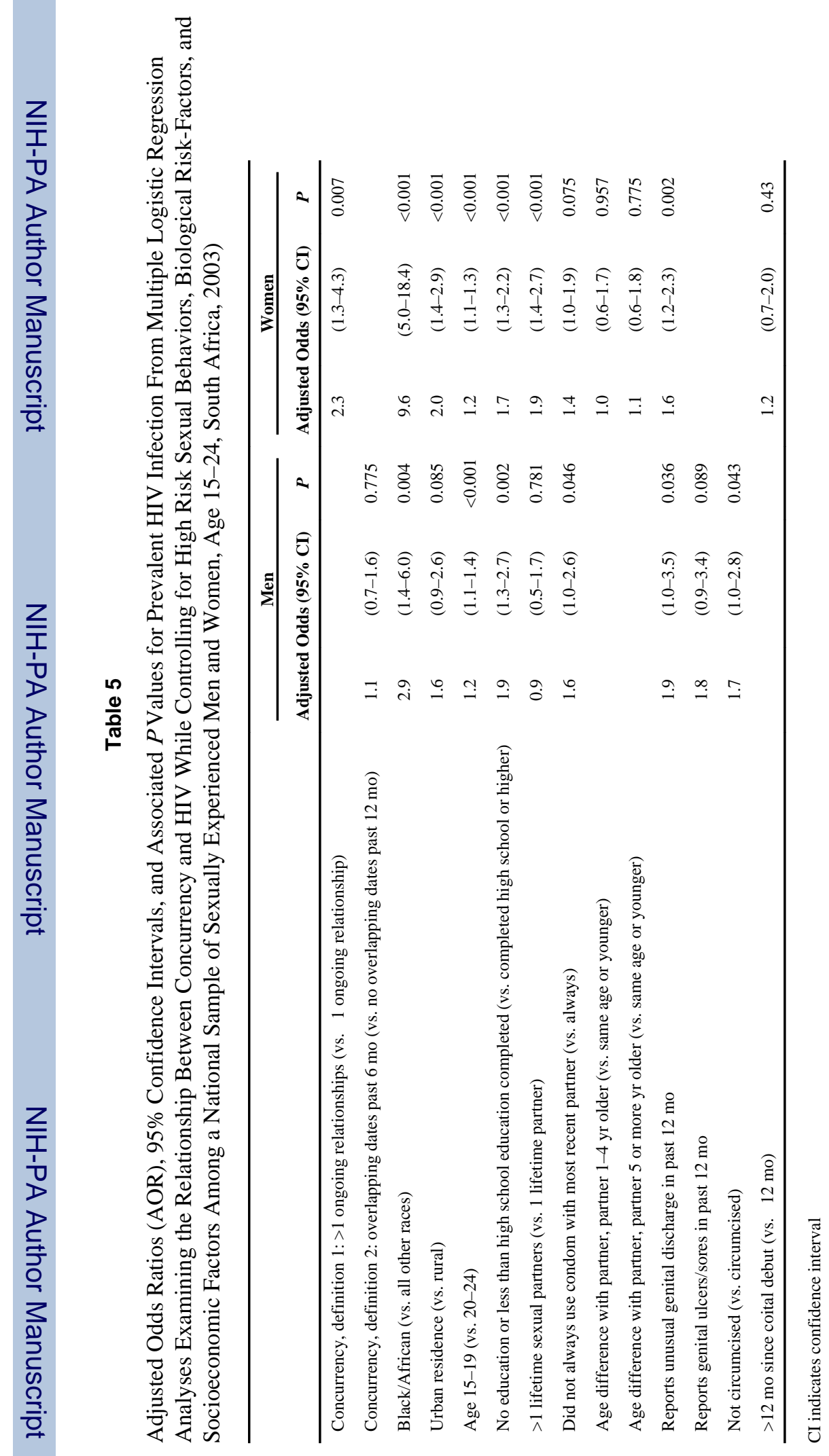

